\title{
Stability Analysis of Steel Welded Tubes Forming Process Using Numerical Simulations
}

\author{
Marko Delić, Vesna Mandić*, Marko Popović
}

\begin{abstract}
In this paper, the research results of the stability of steel welded tubes forming process are presented. The aim of this research is to determine influence of geometrical and tribological parameters on stability of the process and to determine optimal values of influential process parameters. A research plan with variation of influential parameters was made, on the basis of which experimental and numerical experiments were performed. Tube forming was performed in one operation in a two-part tool made of hard metal by a combination of widening and narrowing. The geometrical factors observed during experiments are length, outer diameter and thicknesses of steel welded tube as a billet. Friction conditions in contact between tool and tubular workpiece are considered in two cases, the first one when standard machine oil is used as a lubricant and the second one when tube billet surface is phosphated. Based on results of experiments, influencing factors on stability of tube forming process were analysed and optimal production technology was recommended, including optimal values of influencing factors. Results obtained by experimental research were confirmed through numerical experiments based on finite element method.
\end{abstract}

Keywords: narrowing; numerical analysis; steel welded tubes; widening

\section{INTRODUCTION}

The production of tubular parts has a significant place in the automotive, defence, construction, process industry and energetics. In the past, such parts were made by cutting processes, but nowadays application of forming processes is dominant. The main advantages of producing tubular parts by forming processes are material savings, reduction of production time and production costs.

Tubular parts can be produced by hydro-forming or using widening and narrowing operations. The advantages of production tubular parts by narrowing and widening are lower costs of the necessary equipment and tools. There are several theoretical models which describe the process of tube forming processes by narrowing and widening.

Li et al. [1] proposed a theoretical model of widening metal tubes using a conical tool in the form of a mandrel, which was confirmed by the finite element method. In this model, tool with conical angle $\alpha$ acts along the axis of workpiece at velocity $\mathrm{v}_{0}$. Formed tube was divided into five segments, and the largest strains occurred within two arcs. Based on the assumption of the forming mechanism, total work is spent on plastic bending along the central axis, plastic stretching in the direction of the diameter and on friction in contact zones. Energy consumption for all three processes is described in detail. Experiments have shown that the radius of a tube obtained by widening does not depend on the properties of materials but depends on geometry of tubes and tools.

Methodology for determining deformability limit in thin-walled tubes forming process is presented in paper [2]. Rigid tools are used in the experiment. The test is similar to the Nakajima test. Significance of the boundary deformability diagram is that it provides possibilities for optimizing the tube forming process.

In [3] a model of energy consumption in the forming process of thin-walled tubes is presented. Theoretical model is based on four assumptions. Theoretical analysis explains three deformation models that analyse the process of tube widening. Tube widening process is influenced by geometrical parameters: the ratio of the thickness of the tubular workpiece and the radius and tool inclination angle.

Research results of tube hydro forming process are presented in [4]. Effects of internal pressure, stroke and friction coefficient were analyzed. Taguchi's methods were used to optimize the process. Optimal height of the workpiece was determined based on the response of Taguchi's experiments.

Omar et al. [5] performed investigation of hydro-forming of welded tubes with variation of length and diameter ratio. Mechanical characteristics of the workpiece material and the welded tube seam were determined by tensile test and they are implemented in a numerical process simulation. Tubes are modelled as a system of two materials, the tube and the welded seam materials. Experiments were performed for different values of tube length and diameter. Results of the experiments and numerical simulations agree well and show that the $L / D$ ratio (bulge ratio) has an impact on crack location. For value of ratio $L / D=1$, a crack occurs in the base tube material near the welded seam zone, while for the values of the ratio $L / D=2$ and $L / D=3$ crack occurs on the side opposite to the welded seam zone.

This paper presents research of influence of geometrical factors and friction conditions on the forming process of welded tubes by concurrent combination of widening and narrowing. Geometrical factors of the tube that are considered during analysis are: length, diameter and thickness of the billet tube. Two cases of friction conditions were considered: first one when contact surfaces were lubricated with machine oil and second one when the tube billet surface was phosphated and SAP.G3 soap was used as lubricant. Experimental research was performed and confirmed by numerical simulations in accordance with research plan and combination of influential factors for each experiment. 


\section{THEORETICAL-EXPERIMENTAL RESEARCH OF TUBE FORMING}

There are several methods to obtain products of simple or complex shape from tubular workpiece [6]. Most commonly used forming methods are: narrowing, widening, stretching, upsetting, twisting and combinations of these methods. In literature, there are several technologies of manufacturing the tubular products by forming the ends of tubular workpiece, where the solution to achieve higher strain ratios is found in the installation of holders on the inside or outside of the tube wall to ensure forced flow of material and to avoid forming defects.

Tube narrowing could be done by pulling or pushing material through narrowing ring, which has the final shape of tubular workpiece. Possibility of tube forming by narrowing depends on the narrowing coefficient, which affects the forming load value. Increasing of this load above the limit value leads to cracking or the formation of an annular fold in the non-contact cylindrical zone of the workipece. To make the process of narrowing stable it is necessary that the maximal value of circular stress satisfy the condition $\sigma_{\varphi \max }<$ $\sigma_{\text {critical }}[6]$. Value of the narrowing coefficient needs to be less than 0.8 .

Tube widening occurs under the action of axial force. In the deformation zone, different forms of stress-strain state occur on different cross-sections. In addition to the tool shape, contact friction conditions also have an influence on forming load in tube widening process. The technological possibilities of tube widening are limited by the widening coefficient $k_{\text {wid }}=D_{0} / D_{2}$ [6]. When it is necessary to achieve higher strain ratios in tube widening process it is necessary to have more operations with annealing between those operations. Tubular parts are often produced by combination of narrowing and widening processes.

Hydro-forming of tubular parts is performed using internal pressure, which enables filling of the tool cavity. This method of tube forming is especially suitable for making asymmetrical tubular parts. Application of this technology is limited by the properties of the workpiece material, friction conditions and synchronization of the magnitude of the sealing force and internal pressure. Technological possibilities for application of this technology are quite wide due to the development of modern devices.

As mentioned, the subject of the research presented in the paper is the analysis of the influence of geometrical and friction parameters on the process of forming the tubular part shown in Fig. 1. The geometrical parameters of the tube billet that varied in the experiments are tube wall thickness $\left(s_{0 \mathrm{i}}\right)$, tube diameter $\left(D_{0 \mathrm{i}}\right)$ and tube length $\left(h_{0 \mathrm{i}}\right)$. The selected values of these parameters for the analysis of the stability of the forming process are shown in Tab. 1.

Table 1 Tubular billet dimensions
\begin{tabular}{|l|c|c|c|}
\hline & $i=1$ & $i=2$ & $i=3$ \\
\hline Tube wall thickness $\left(s_{0 \mathrm{i}}\right)$ & $2 \mathrm{~mm}$ & $2.33 \mathrm{~mm}$ & $2.5 \mathrm{~mm}$ \\
\hline Tube diameter $\left(D_{0 \mathrm{i}}\right)$ & $31 \mathrm{~mm}$ & $32 \mathrm{~mm}$ & $33 \mathrm{~mm}$ \\
\hline Tube length $\left(h_{0 \mathrm{i}}\right)$ & $68.5 \mathrm{~mm}$ & $69 \mathrm{~mm}$ & $69.5 \mathrm{~mm}$ \\
\hline
\end{tabular}

In order for the narrowing process at the ends of the tube billet to be successful, the narrowing force must overcome:

- resistance to narrowing of the non-contact and contact zone,

- bending resistance at the transition radius of the narrowing and

- resistance to narrowing in the conical part.

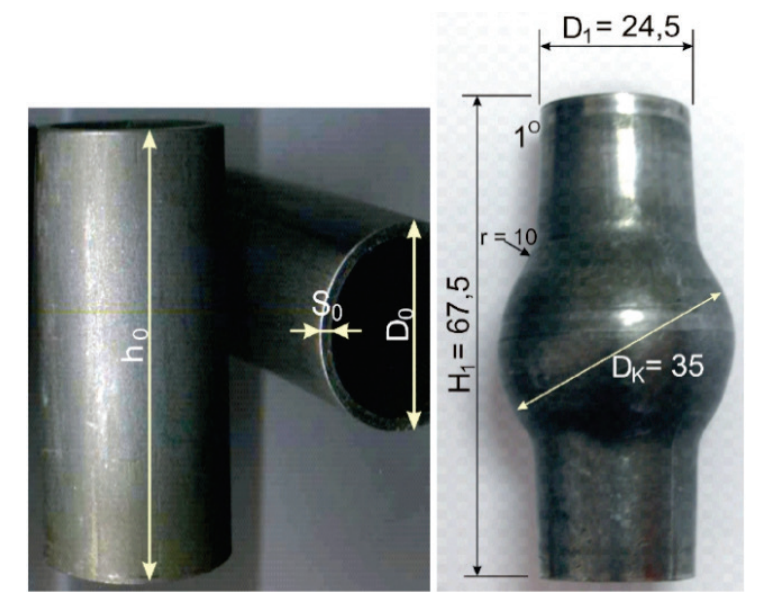

Figure 1 Geometrical characteristics of tubular billet and final workpiece $[6,7]$

During the forming process, an uneven distributions of strain and stresses occur. According to [7], the stress state in the combined widening and narrowing forming process is considered in five different deformation zones. The deformation zones, shown in Fig. 2, in the phases of tube narrowing process are:

1) zone of free compression of the cylindrical part of the tube,

2) deformation zone without contact,

3) narrowing zone in the spherical part of the ring,

4) bending zone on radius and

5) narrowing zone in the conical part.
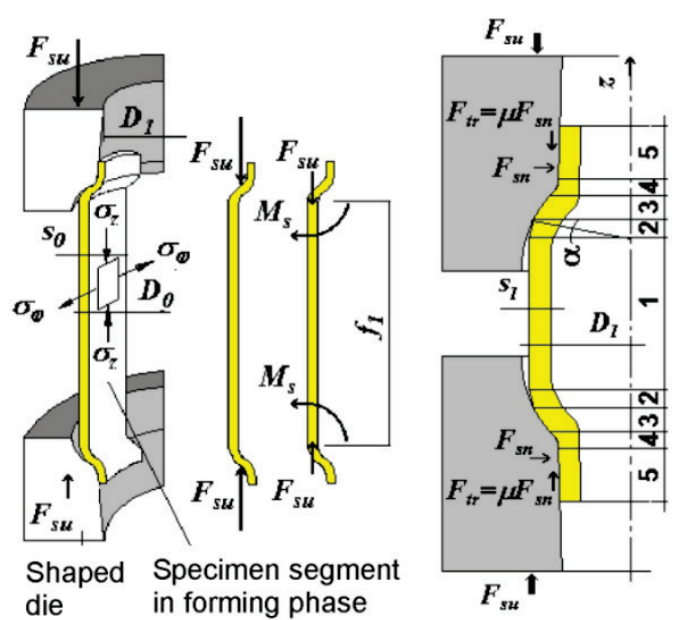

Figure 2 Action of forces and stress state during forming (left) and deformation zones during tube narrowing (right) $[6,7]$

There are many design solutions for narrowing and widening tools. The concept of a two-part tool was chosen, which simultaneously narrows and expands the tubular 
workpiece to obtain the shape of a calotte in its central part. Tool consists of two shaping spherical parts made of hard metal, with PV20 quality (Fig. 3).

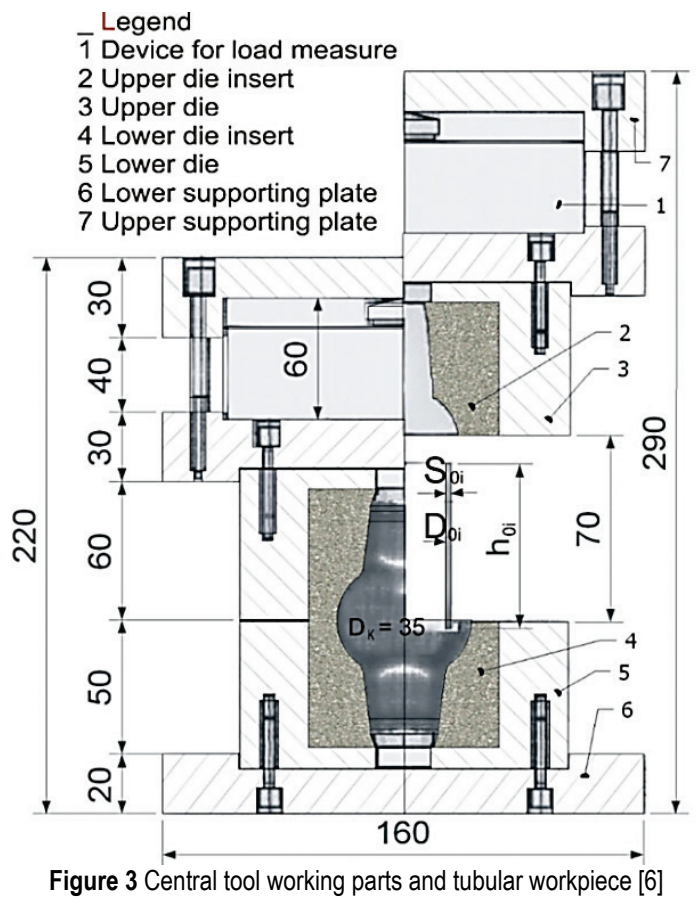

Coefficient of narrowing and the coefficient of widening are important parameters in the process of the tube forming. Coefficient of narrowing is the ratio of diameter of the narrowed part and the initial tube billet diameter and in the case of the selected dimensions of workpiece, given in Tab. 1 , the coefficient has following values:

$k_{\text {nar }}=\frac{D_{1}}{D_{\mathrm{oi}}}=(0.79,0.76,0.74)$.

Widening coefficient is the ratio of initial diameter of the tube and diameter of widened tube and for the selected combinations of geometrical parameters, corresponding coefficient values are:

$k_{\text {wid }}=\frac{D_{\mathrm{oi}}}{D_{\mathrm{k}}}=(0.88,0.91,0.94)$.

Conducted experiments according to the research plan and by varying the influential geometrical parameters showed that the successful tube forming was achieved by combining the parameters of the tube billet $s_{2} h_{2} D_{2}$ that had a previous chemical preparation and lubricated by SAP.G3 soap, i.e. for the deformation coefficient:

$k_{\text {def }}=k_{\text {nar }} \cdot k_{\text {wid }}=0.76 \cdot 0.91=0.69$.

\section{EXPERIMENTAL AND NUMERICAL RESEARCH}

Process of narrowing and widening were performed on a hydraulic press with a nominal force of $320 \mathrm{kN}$, at a deformation velocity of $v=0.023 \mathrm{~m} / \mathrm{s}$. After forming, the tube workpiece is additionally joined by welding with the side tube parts to obtain a T-connector. After considering all technical requirements, the material S235 JRG2 was selected for tube workpiece, as this material has good weldability. Since the workpiece is obtained by cutting to a certain length of welded tubes, it is necessary to consider the mechanical properties of the material after obtaining welded tubes from steel strips. During the forming of welded tubes, the deformability of the material is reduced by up to $18 \%$ in relation to the samples from the strip. Due to these facts, it is necessary to determine the characteristics of the base steel strip material and the material of the formed welded tubes.

For testing mechanical properties of workpiece material it was used uniaxial tensile test. Two types of samples were prepared, a standard sample punched from steel strip before bending of tube and a sample punched from formed and welded tube. Experimentally obtained flow curves are shown in Fig. 4, and they can be approximated in analytical form. Flow curve obtained by testing samples from steel strips can be represented by the analytical model:

$$
K=C \cdot \varphi^{n}=677 \cdot \varphi^{0.168} .
$$

Flow curve obtained by testing samples from steel welded tubes has the form:

$$
K=C \cdot \varphi^{n}=616 \cdot \varphi^{0.064}
$$

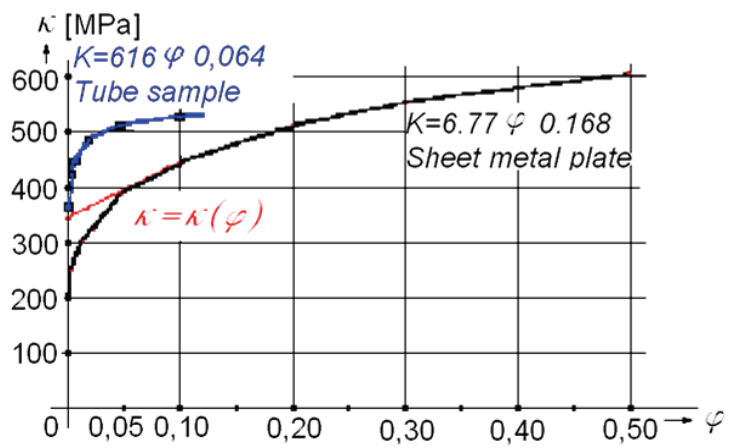

Figure 4 Flow curves obtained by material testing before and after forming of the steel welded tube [6]

Coefficients (factors) of friction were determined by a ring compression test [6]. In the case when machine oil is used as a lubricant, value of the friction coefficient/factor $\mu$ $=0.13(m=0.225)$ was obtained, and in case of chemically treated workpiece surfaces, respective values are $\mu=0.095$ $(m=0.164)$.

Considering influence of geometrical factors and influence of friction conditions on the stability of the forming process, a plan of experiments was made. Combinations of geometric parameters of the tube billet, shown in Tab. 1, were obtained by factor analysis. By varying these three 
geometrical parameters, it is possible to determine influence of their mutual interaction on the stability of forming process. In addition to the three geometrical factors, two cases of lubrication were considered:

- lubrication with machine oil and

- $\quad$ chemically treated surface (phosphated) with SAP.G3 soap.

While forming tubular workpiece, it is necessary that the surface of the workpiece be chemically prepared - by phosphating. However, one part of the experiments was performed without chemical surface preparation in order to analyze the influence of friction conditions on appearance of defects during forming, so lubrication was performed using only machine oil. Plan of experiments when machine oil is used for lubrication is shown in the Tab. 2.

Table 2 Experiment plan (lubricant: machine oil)

\begin{tabular}{|c|c|l|}
\hline No. & Experiment code & Combination of geometrical parameters \\
\hline 1 & $s_{1} h_{1} D_{1}$ & $s_{1}=2 \mathrm{~mm} ; h_{1}=68.5 \mathrm{~mm} ; D_{1}=31 \mathrm{~mm}$ \\
\hline 2 & $s_{1} h_{1} D_{3}$ & $s_{1}=2 \mathrm{~mm} ; h_{1}=68.5 \mathrm{~mm} ; D_{3}=33 \mathrm{~mm}$ \\
\hline 3 & $s_{3} h_{1} D_{3}$ & $s_{3}=2.5 \mathrm{~mm} ; h_{1}=68.5 \mathrm{~mm} ; D_{3}=33 \mathrm{~mm}$ \\
\hline 4 & $s_{3} h_{1} D_{1}$ & $s_{3}=2.5 \mathrm{~mm} ; h_{1}=68.5 \mathrm{~mm} ; D_{1}=31 \mathrm{~mm}$ \\
\hline 5 & $s_{1} h_{3} D_{1}$ & $s_{1}=2 \mathrm{~mm} ; h_{3}=69.5 \mathrm{~mm} ; D_{1}=31 \mathrm{~mm}$ \\
\hline 6 & $s_{2} h_{2} D_{1}$ & $s_{2}=2.33 \mathrm{~mm} ; h_{2}=69 \mathrm{~mm} ; D_{1}=31 \mathrm{~mm}$ \\
\hline 7 & $s_{2} h_{2} D_{2}$ & $s_{2}=2.33 \mathrm{~mm} ; h_{2}=69 \mathrm{~mm} ; D_{2}=32 \mathrm{~mm}$ \\
\hline 8 & $s_{3} h_{2} D_{1}$ & $s_{3}=2.5 \mathrm{~mm} ; h_{2}=69 \mathrm{~mm} ; D_{1}=31 \mathrm{~mm}$ \\
\hline 9 & $s_{3} h_{3} D_{1}$ & $s_{3}=2.5 \mathrm{~mm} ; h_{3}=69.5 \mathrm{~mm} ; D_{1}=31 \mathrm{~mm}$ \\
\hline 10 & $s_{3} h_{3} D_{1}$ & $s_{3}=2.5 \mathrm{~mm} ; h_{3}=69.5 \mathrm{~mm} ; D_{1}=31 \mathrm{~mm}$ \\
\hline 11 & $s_{3} h_{3} D_{3}$ & $s_{3}=2.5 \mathrm{~mm} ; h_{3}=69.5 \mathrm{~mm} ; D_{3}=33 \mathrm{~mm}$ \\
\hline
\end{tabular}

Advantages of forming without chemical surface preparation are lower cost and shorter production time. However, numerous defects occurred during the forming of the tube without chemical surface preparation, such as the appearance of a double bulge and overfilling or insufficient filling of the calotte, as shown in Fig. 5. On the tubular workpieces that are irregularly formed, it has been observed that the appearance of process instability occurs in different stages of forming process. On the workpieces shown in Figs. $4 \mathrm{a}$ and $4 \mathrm{~b}$, forming instability occurred at the very beginning of the process, so double folds and depressions were formed. In the other two workpieces, in the same figure, the instability of the process occurred at the end, with the appearance of excess material and its flow in the calotte zone.

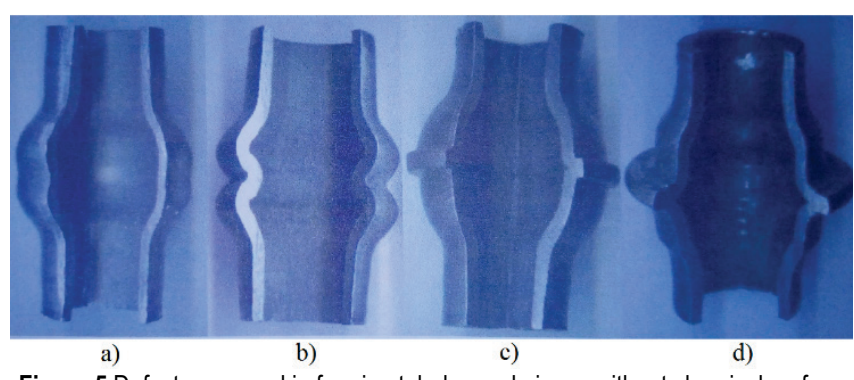

Figure 5 Defects occurred in forming tubular workpieces without chemical surface preparation

Since the experiments in which machine oil was used for lubrication showed poor results, a second set of experiments was made in which the surfaces of the workpieces were chemically treated. Chemical surface preparation includes degreasing and pickling of the tube billet surface in $\mathrm{H}_{2} \mathrm{SO}_{4}$ solution, then rinsing it with water, and then immersion in protectan 27. After the phosphating procedure, a quality SAP.G3 soap lubricant was applied. The goal is to improve the friction conditions and to enable the proper flow of material in the tool, without the appearance of defects. Plan of the experiments is shown in the Tab. 3 .

Table 3 Experiment plan (lubricant: Zn phosphat + SAP.G3)

\begin{tabular}{|c|c|l|}
\hline No. & Experiment code & \multicolumn{1}{|c|}{ Combination of geometrical parameters } \\
\hline 1 & $s_{1} h_{1} D_{1}$ & $s_{1}=2 \mathrm{~mm} ; h_{1}=68.5 \mathrm{~mm} ; D_{1}=31 \mathrm{~mm}$ \\
\hline 2 & $s_{1} h_{3} D_{1}$ & $s_{1}=2 \mathrm{~mm} ; h_{3}=69.5 \mathrm{~mm} ; D_{1}=31 \mathrm{~mm}$ \\
\hline 3 & $s_{2} h_{2} D_{2}$ & $s_{2}=2.33 \mathrm{~mm} ; h_{2}=69 \mathrm{~mm} ; D_{2}=32 \mathrm{~mm}$ \\
\hline 4 & $s_{3} h_{1} D_{3}$ & $s_{3}=2.5 \mathrm{~mm} ; h_{1}=68.5 \mathrm{~mm} ; D_{3}=33 \mathrm{~mm}$ \\
\hline 5 & $s_{3} h_{2} D_{1}$ & $s_{3}=2.5 \mathrm{~mm} ; h_{2}=69 \mathrm{~mm} ; D_{1}=31 \mathrm{~mm}$ \\
\hline 6 & $s_{3} h_{3} D_{3}$ & $s_{3}=2.5 \mathrm{~mm} ; h_{3}=69.5 \mathrm{~mm} ; D_{3}=33 \mathrm{~mm}$ \\
\hline 7 & $s_{2} h_{1} D_{2}$ & $s_{2}=2.33 \mathrm{~mm} ; h_{1}=68.5 \mathrm{~mm} ; D_{2}=32 \mathrm{~mm}$ \\
\hline 8 & $s_{2} h_{3} D_{2}$ & $s_{2}=2.5 \mathrm{~mm} ; h_{3}=69.5 \mathrm{~mm} ; D_{2}=32 \mathrm{~mm}$ \\
\hline 9 & $s_{2} h_{2} D_{1}$ & $s_{2}=2.33 \mathrm{~mm} ; h_{2}=69.5 \mathrm{~mm} ; D_{1}=31 \mathrm{~mm}$ \\
\hline 10 & $s_{2} h_{2} D_{3}$ & $s_{2}=2.33 \mathrm{~mm} ; h_{2}=69 \mathrm{~mm} ; D_{3}=33 \mathrm{~mm}$ \\
\hline
\end{tabular}

For all experiments that were realized in accordance with the described plans, numerical simulations were realized using the finite element method and Simufact forming software. Simufact forming software uses MSC Marc solver for finite element calculations, based on the deformation method [8].

Due to the symmetry of the tubular workpiece, a 2D analysis was performed, which significantly reduced the time required for the simulation. The input data for numerical process simulations are shown in Tab. 4.

Table 4 Input data for numerical simulations

\begin{tabular}{|l|l|}
\hline Simulation type & 2D \\
\hline Mesher type & Advancing front quad \\
\hline Element type & Quads $(10)$ \\
\hline Element size & $0.3 \mathrm{~mm}$ \\
\hline Number of elements & 1610 \\
\hline Friction conditions & $\begin{array}{l}\text { Combined } \\
(\mu=0.095 ; m=0.164) \text { - chemically prepared } \\
\text { surface } \\
(\mu=0.13 ; m=0.225) \text { - lubrication with } \\
\text { machine oil }\end{array}$ \\
\hline Flow curve & $K=677 \varphi^{0.168}$ \\
\hline Stroke & $70 \mathrm{~mm}$ \\
\hline
\end{tabular}

\section{ANALYSIS OF THE RESULTS OF EXPERIMENTAL AND NUMERICAL PROCESS MODELLING}

The results of the experiments showed that in the case of lubrication with machine oil, the calotte is poorly filled or wrinkles and folds appear, which is completely confirmed by numerical simulations. A comparative representation of the defects that occur during the forming of the workpiece with the geometrical parameters $s_{3} h_{3} D_{3}$ is shown in Fig. 6 .

Experiments in which the workpieces were immersed in a solution of SAP.G3 after phosphating showed better process stability, but it was still conditioned by combinations of geometrical parameters. Under such contact conditions, in case of workpiece with a diameter of $D_{3}$, calotte was 
overfilled and defects appear, while in the case of workpiece with a diameter of $D_{1}$, calotte was incompletely filled.
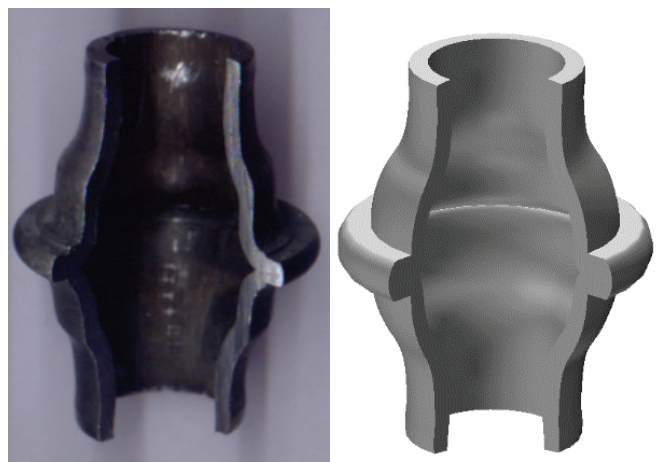

Figure 6 Comparison of the results of physical and numerical experiments $s_{3} h_{3} D_{3}$ when machine oil is used as a lubricant $[6,7]$

Influence of workpiece geometrical parameters for appearance of defects and instability of the forming process was additionally analyzed by numerical experiments. Results of some of them are shown in Fig. 7. If we observe the influence of the diameter of the tube billet on the appearance of defects and the stability of the process, the left part of the Fig. 7 shows a virtual workpiece with an unfilled callote and tool for the applied billet of diameter $D_{1}$. Good process stability was confirmed for the tube billet of diameter $\mathrm{D}_{2}$ (in the middle) and the effect of overfilling of tool and folding defect in the part of the calotte is evident in forming the tube billet of diameter $\mathrm{D}_{3}$ (right part of the picture).
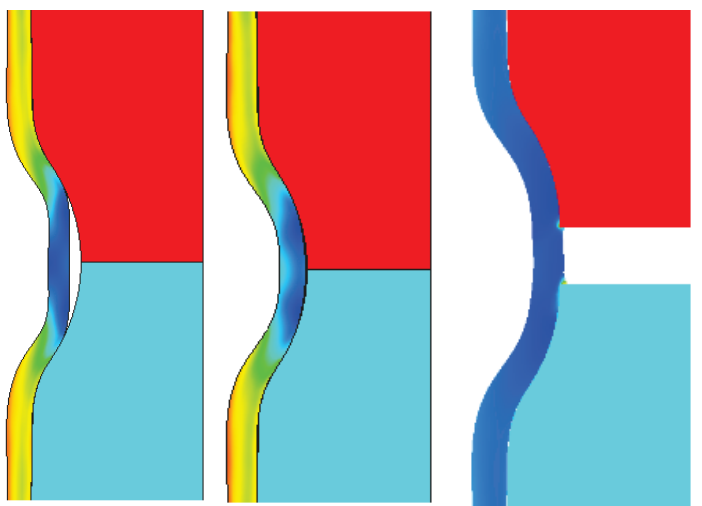

Figure 7 Unfilled calotte $\left(s_{1} h_{1} D_{1}\right)$, well filled calotte $\left(s_{2} h_{2} D_{2}\right)$, overfilled calotte $\left(s_{3} h_{3} D_{3}\right)$ of tubular workpiece

Best forming results and thus the precision of the tube product were achieved with the tube billet dimensions of the $s_{2} h_{2} D_{2}$. A comparative representation of a properly formed workpiece is shown in Fig. 8.

Numerical experiments confirmed that the process in the case of chemically prepared workpiece surface and lubrication with SAP.G3 solution is stable and that the filling of the calotte is adequate. The material flow during the forming of the tubular workpiece $s_{2} h_{2} D_{2}$ obtained by numerical simulation of the process is shown in Fig. 9.

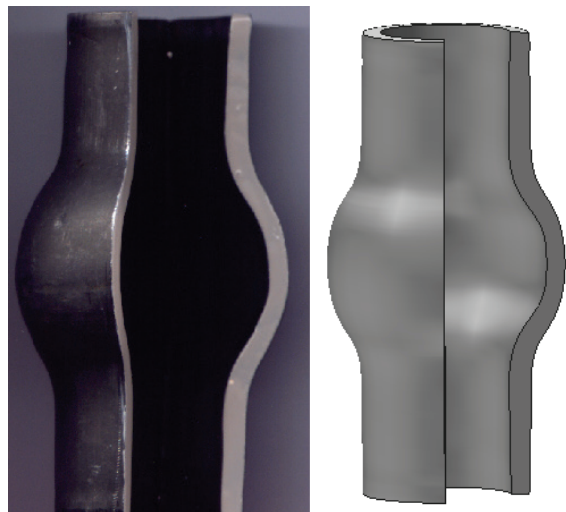

Figure 8 Properly deformed part obtained experimentally (left) and by numerical simulation (right)
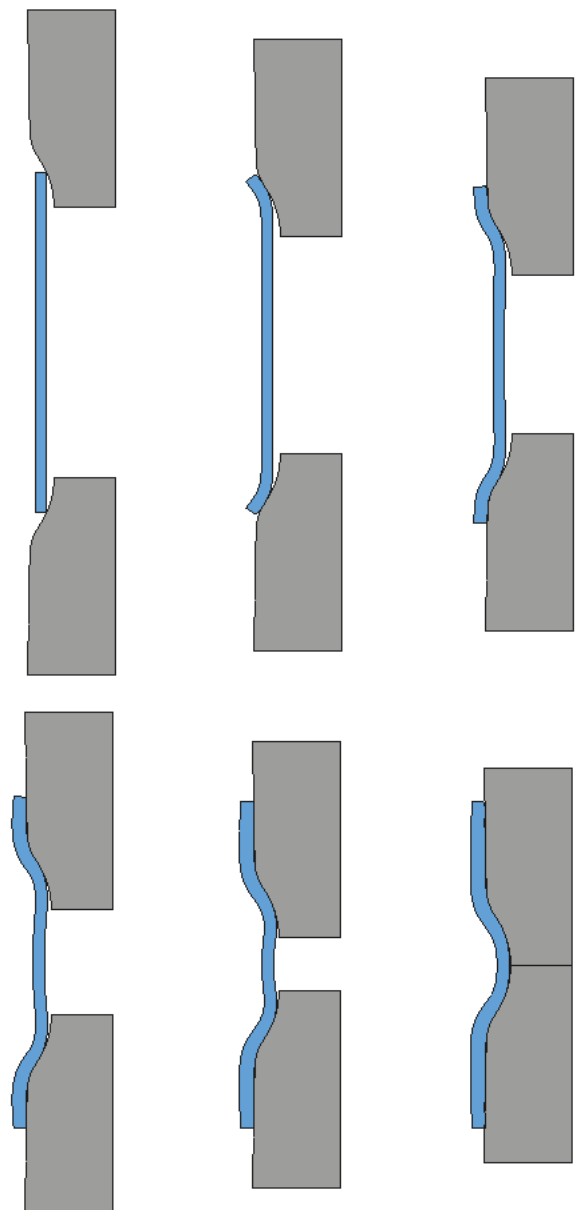

Figure 9 Numerical simulation of material flow during forming process (phosphated workpiece surface + SAP.G3 $-s_{2} h_{2} D_{2}$ )

Distributions of the effective stress and the effective plastic strain in the tubular workpiece for the combination of geometrical parameters $s_{2} h_{2} D_{2}$ with the chemically prepared tube billet surfaces are shown in Fig. 10. In Fig. 10 is shown that highest values of plastic strain and effective stress are in narrowed part. The minimum values of effective plastic strain (Fig. 10b) are in the area of the calotte where the smallest wall thickening occurred. 


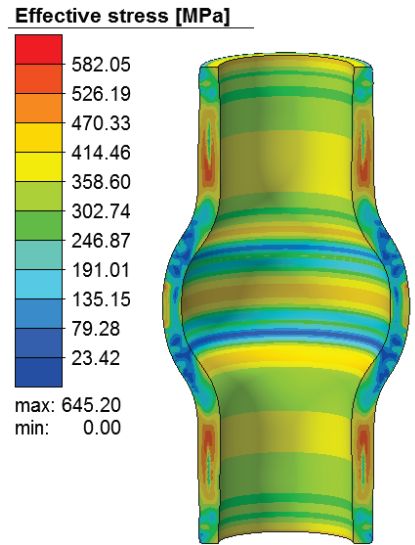

a)

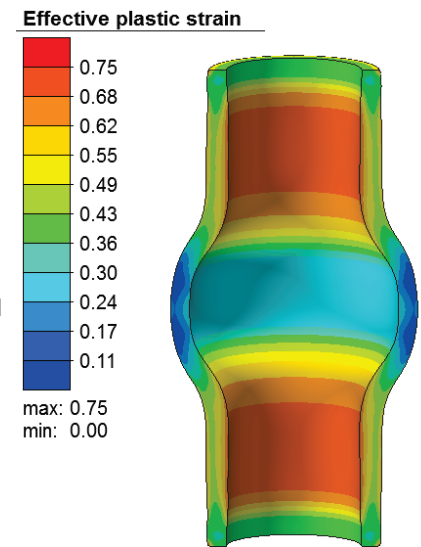

b)
Figure 10 Distributions of effective stress (a) and effective plastic strain b) obtained by numerical simulation of forming tubular workpiece $s_{2} h_{2} D_{2}$

Maximum values of the forming loads registered experimentally and calculated by numerical simulations are shown in the Tab. 5.

Table 5 Maximum forming load values - obtained experimentally and numerically

\begin{tabular}{|c|c|c|}
\hline Experiment code & $\begin{array}{c}\text { Forming load }- \\
\text { experiment }(\mathrm{kN})\end{array}$ & $\begin{array}{c}\text { Forming load - } \\
\text { numerical }(\mathrm{kN})\end{array}$ \\
\hline$s_{2} h_{1} D_{2}$ & 85 & 98 \\
\hline$s_{2} h_{2} D_{2}$ & 102 & 99 \\
\hline$s_{2} h_{3} D_{2}$ & 102 & 101,9 \\
\hline$s_{2} h_{2} D_{1}$ & 101 & 92,1 \\
\hline$s_{2} h_{2} D_{3}$ & 113 & 117,9 \\
\hline
\end{tabular}

It is noticeable that at constant values of workpiece diameter and the wall thickness, and with increasing the workpiece length, there is an increase of the maximum forming load value. When the wall thickness and the workpiece length are constant and the workpiece diameter increases, there is also an increase of the forming load.

Comparison of forming load diagrams obtained experimentally and numerically for optimal geometrical parameters and lubrication conditions in the $s_{2} h_{2} D_{2}$ experiment is shown in Fig. 11. Figs. 12 and 13 show a comparison of the forming load diagrams obtained experimentally and numerically for the case when tube billet diameters are $D_{1}$ and $D_{3}$. As the diameter of the tube billet increases, the required shaping force increases. Increasing the diameter increases required forming load. The comparative diagrams and values shown in Tab. 5 show a satisfactory agreement of the experimental and numerical results of the tube forming process analysis.

Based on the analysis of all results, it can be concluded that the forming of the steel welded tubes using machine oil as lubricant is not satisfactory. When experiments were performed with tube billets whose surfaces were chemically treated, the optimal combination of geometrical parameters of the billet with the values $s_{2} h_{2} D_{2}\left(s_{2}=2.33 \mathrm{~mm} ; h_{2}=69\right.$ $\mathrm{mm} ; D_{2}=32 \mathrm{~mm}$ ) was determined. It is interesting to note that even in the case of lubrication with machine oil, this combination of parameters gives better results, but the diameter of the calotte and the dimensional accuracy of the tube final part are not achieved.

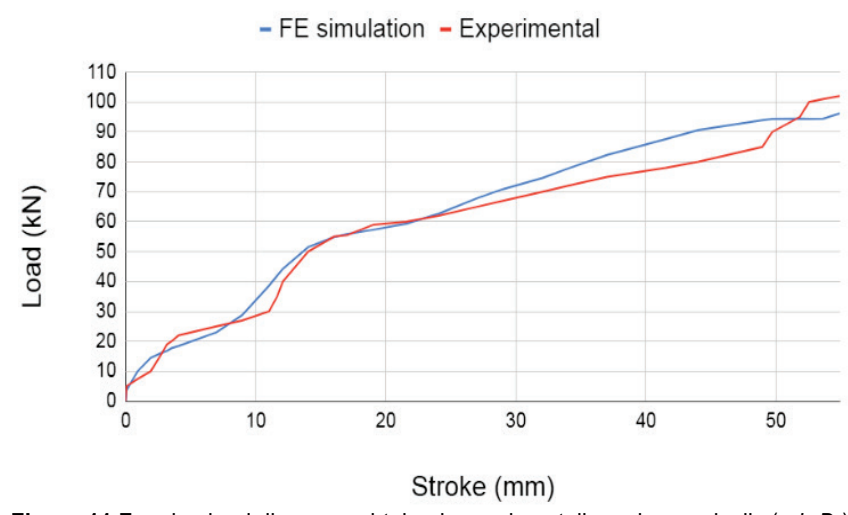

Figure 11 Forming load diagrams obtained experimentally and numerically $\left(s_{2} h_{2} D_{2}\right)$

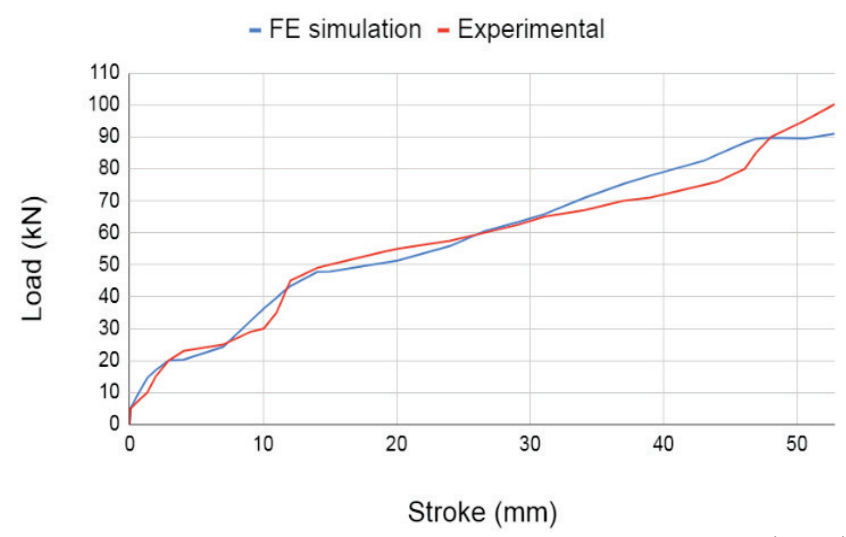

Figure 12 Forming load diagrams obtained experimentally and numerically $\left(s_{2} h_{2} D_{1}\right)$

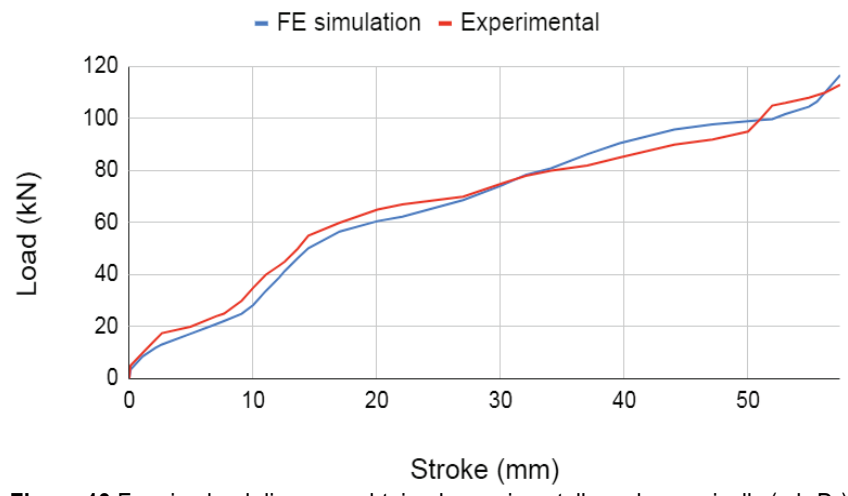

Figure 13 Forming load diagrams obtained experimentally and numerically $\left(s_{2} h_{2} D_{3}\right)$

\section{CONCLUSION}

Forming of tubular parts in tools on presses with a combination of narrowing and widening is possible to produce parts of complex geometry and good dimensional accuracy with low production cost.

For successful production, it is necessary to correctly determine the values of the geometrical parameters of the tube billet. Best forming results in experiments and numerical simulations were achieved for the tubular billet geometrical parameters $s_{2} h_{2} D_{2}\left(s_{2}=2.33 \mathrm{~mm}, h_{2}=69 \mathrm{~mm}\right.$, $D_{2}=32 \mathrm{~mm}$ ), i.e. for values of narrowing coefficient $k_{\mathrm{nar}}=$ 0.76 and the widening coefficient $k_{\text {wid }}=0.91$. From results of the experiments for this example, it can be concluded that the forming process is stable for the ratio of the geometrical 
dimensions of workpieces $s_{0} / D_{0} \cong 0.07, D_{0} / h_{0} \cong 0.46$ and $k_{\mathrm{su}} / k_{\mathrm{pr}} \cong 0.84$. When the values of the coefficients of narrowing and widening change at the same dimensions of the tube billet, unsatisfactory filling of the calotte or its overfilling occur. When designing this forming technology for similar tubular parts it should be planned that the ratio of the coefficient of narrowing and widening should be in the range from 0.78 to 0.89 . Moreover, one should also take into account the fact that increasing tube billet diameter, wall thickness or length increases the forming load.

Results of the experiments and numerical simulations confirm that the friction conditions, i.e. lubrication has a great influence on the stability of forming process of welded tubes by narrowing and widening. Thus, the selection of an appropriate lubricant and chemical preparation of the tubular billet are an essential for obtaining quality parts in the sable forming process. In experiments where workpiece surface was not chemically treated, but only machine oil was used for lubrication, the forming process proved to be unstable. Unfavorable friction conditions in the first set of experiments, where tube billet surfaces were not chemically treated, led to an increase in the narrowing force and difficult flow of the material, which resulted in the appearance of process instability and defects on the workpiece. It was concluded that it is necessary to reduce effect of contact friction through chemical preparation (phosphating) of tubular billet surfaces and application of SAP.G3 soap as a lubricant.

The matching of the results obtained experimentally and numerically shows the advantages of complementary application of the finite element method and numerical simulations of the forming processes in the analysis of influential process parameters on its stability, technology optimization and elimination of forming defects.

\section{Acknowledgments}

The authors wish to acknowledge the financial support from the Ministry of Education and Science of the Republic of Serbia through the project TR 34002.

\section{Notice}

The paper will be presented at MOTSP $2021-12^{\text {th }}$ International Conference Management of Technology - Step to Sustainable Production, which will take place in Poreč/Porenzo, Istria (Croatia), on September 8-10, 2021. The paper will not be published anywhere else.

\section{REFERENCES}

[1] Liu, Y. \& Qiu, X.-M. (2016). A theoretical study of the expansion metal tubes. International Journal of Mechanical Sciences, 114, 157-165. https://doi.org/10.1016/j.jmecsci.2016.05.014

[2] Magrinho, J. P., Silva, M. B., Centeno, G., Moedas, F., Vallellano, C., \& Martins, P. A. F. (2019). On the determination of forming limits in thin-walled tubes. International Journal of Mechanical Sciences, 155, 381-391. https://doi.org/10.1016/j.jimecsci.2019.03.020

[3] Luo, M., Yang, J., Liu, H., Lu, G., \& Yu, J. Energy absorption of expansion tubes using a conical-cylindrical die: Theoretical model. International Journal of Mechanical Sciences, 157158, 207-220. https://doi.org/10.1016/j.jmecsci.2019.04.033

[4] Venkateshwar Reddya, P., Veerabhadra Reddyb, B., \& Srinivasa Rao, P. (2018). A Numerical Study on Tube Hydroforming Process to optimize the Process Parameters by Taguchi Method. Materials Today: Proceedings, 2537625381. https://doi.org/10.1016/j.matpr.2018.10.341

[5] Omar, A., Tewari, A., \& Narasimhan, K. (2020). Effect of bulge ratio on the deformation behaviour and fracture location during welded steel tube hydroforming process. Results in Materials, 6. https://doi.org/10.1016/j.rinma.2020.100096

[6] Mišić, B. (2004). Stability of the process of narrowing of products from steel welded tubes (in Serbian), Doctoral dissertation, Faculty of Mechanical Engineering, Banja Luka.

[7] Mandić, V., Stefanović, M., Živković, M., Grujović, N., \& Mišic, B. (2006). FE analysis of tube forming process with experimental verification. Journal of Achievements in Materials and Manufacturing Engineering, 18, 303-306.

[8] Mandić, V. (2012). Physical and numerical modelling of forming processes (in Serbian), Faculty of Mechanical Engineering, Kragujevac.

\section{Authors' contacts:}

Marko Delić, Teaching assistant Faculty of Engineering of the University of Kragujevac, Sestre Janjić 6, 34000 Kragujevac, Serbia marko.delic@kg.ac.rs

Vesna Mandić, Full professor

(Corresponding author)

Faculty of Engineering of the University of Kragujevac,

Sestre Janjić 6, 34000 Kragujevac, Serbia

mandic@kg.ac.rs

Marko Popović, MSc Mech. Eng.

Gorenje MDM,

Kosovska 4, 34000 Kragujevac, Serbia

marko.popovic@gorenje-mdm.com 